\title{
HISTÓRIA E FILOSOFIA DA CIÊNCIA NA EDUCAC̣ÃO CIENTÍFICA: PARA QUÊ?
}

\author{
Felipe Damasio* \\ Luiz 0. Q. Peduzzi**
}

RESUMO: Neste trabalho, descreve-se uma revisão bibliográfica em dissertações de mestrados e teses de doutorado no último decênio, que tecem considerações acerca da abordagem didática de história e filosofia da ciência na educação científica. A análise procurou, em um primeiro momento, identificar as referências filosóficas e pedagógicas declaradas pelos autores. A seguir, a investigação buscou os objetivos manifestados pelos autores para o uso didático da história e filosofia da ciência, também se e como eles articulam os referenciais adotados com a abordagem na educação científica de história e filosofia da ciência. Os resultados mostram que, com frequência, um aporte teórico, filosófico e metodológico está ausente. Bem como, quando existe tal fundamentação, há regularmente ausência da articulação e coerência entre elas. Como possíveis conclusões, os resultados podem e devem causar uma reflexão em relação ao desenvolvimento e credibilidade da própria área de pesquisa em educação científica.

Palavras-chave: Revisão bibliográfica. História da ciência. Educação científica.

\section{SCIENCE HISTORY AND PHILOSOPHY IN SCIENTIFIC EDUCATION: WHAT FOR?}

ABSTRACT: This paper describes a literature review in master's dissertations and doctoral thesis in the last decade that comment about the didactic approach to history and philosophy of science in science education. The analysis sought at first to identify the philosophy and pedagogical references declared by the authors. Following, the investigation sought the objectives expressed by the authors for the didactic use of history and philosophy of science, and also how they articulate the benchmarks adopted with the approach in basic education of history and philosophy of science. The results show that often a theoretical, philosophical and methodological approach are missing. And when there is such a basis, there is regularly absence of coordination and coherence between them. As possible conclusions, the results can and should cause a reflection in relation to the development and credibility of the research area of science education.

Keywords: Literature review. History of science. Scientific education.
*Instituto Federal de Santa Catarina (IFSC), Florianópolis, SC - Brasil. Doutorando em Educação Científica e Tecnológica (UFSC). Professor do Instituto Federal de Santa Catarina (IFSC). E-mail: < felipedamasio@ifsc.edu.br >.

* * Universidade Federal de Santa Catarina (UFSC), Florianópolis, SC - Brasil. Doutor em Ensino de Ciências Naturais e Matemática (UFSC). Professor do Departamento de Física e Programa de Pós-Graduação em Educação Científica e Tecnológica da UFSC. E-mail: < luiz.peduzzi@ufsc.br>. 
HISTORIA Y FILOSOFÍA DE LAS CIENCIAS EN LA EDUCACIÓN CIENTÍFICA: ¿PARA QUÉ?

RESUMEN: En este trabajo, describimos una revisión bibliográfica en tesis de maestría y doctorado en el último decenio, que tejen consideraciones acerca del abordaje didáctico de historia y filosofía de las ciencias en la educación científica. El análisis buscó, en un primer momento, identificar las referencias filosóficas y pedagógicas declaradas por los autores. Enseguida, la investigación buscó los objetivos manifestados por los autores para el uso didáctico de la historia y de la filosofía de las ciencias, así como sí y cómo ellos articulan los referenciales adoptados con el abordaje en la educación científica de historia y filosofía de las ciencias. Los resultados muestran que, frecuentemente, un aporte teórico, filosófico y metodológico está ausente. Bien como, cuando existe tal fundamentación, está regularmente auséntela articulación y coherencia entre ellas. Como posibles conclusiones, los resultados pueden y deben causar reflexión respeto al desarrollo y credibilidad del propio campo de investigación en educación científica.

Palabras clave: Revisión Bibliográfica. Historia de las Ciencias. Educación Científica. 


\section{INTRODUĈ̣̃O}

A educação científica é distinta do treinamento científico (MOREIRA, 2004). $\mathrm{O}$ treinamento está dirigido à atividade de fazer ciência, para teorias e procedimentos úteis neste contexto. Por sua vez, a educação científica procura dar meios para que os estudantes possam interpretar o mundo de acordo com o olhar científico, manipulando os conceitos, leis e procedimentos da ciência quando enfrentam algum problema. Ela ainda possibilita que os alunos sejam capazes de identificar aspectos históricos, filosóficos, sociais e culturais das ciências, não requerendo que se "coloque o aluno no laboratório", ou se "transformem estudantes em especialistas", tampouco "eduquem o aluno como um pesquisador em potencial".

A pesquisa em educação científica, por sua vez, pode ser entendida como a produção de conhecimento sobre a educação científica. Essa atividade busca respostas para questões relacionadas ao ensino e aprendizagem, currículo e contexto educativo, além de questões sobre a formação inicial e continuada de professores (ibid.). A pesquisa em educação científica iniciou na década de 1970 e consolidou-se na década seguinte (MOREIRA, 2000).

Atualmente, muitos pesquisadores em educação científica defendem o caráter pedagógico da história da ciência (MATTHEWS, 1995; BASTOS, 1998; PEDUZZI, 2001; GUERRA et al, 2004; MARTINS, 2007; FORATO et al, 2011; RAICIK e Peduzzi, 2015). Teixeira et al (2009) fizeram um levantamento em periódicos internacionais em artigos em língua inglesa sobre o uso didático da história e filosofia da ciência. Os autores encontraram 152 artigos publicados entre 1940 e 2008 que defendiam tal abordagem. Desses, após alguns critérios de exclusão, analisaram 11 estudos. A maioria dos estudos examinados por Teixeira et al associava a pertinência do uso da história e filosofia da ciência buscando a mudança conceitual, procurando traçar semelhanças entre as concepções alternativas dos alunos e a evolução histórica dos conceitos científicos. No entanto, conforme ressaltam os autores, atualmente este paralelismo sofre duras críticas, entre outras coisas, porque implica uma visão acumulativa e linear do empreendimento científico. Outros objetivos evidenciados pelos autores para o uso didático de história e filosofia da ciência foram: alcançar melhor compreensão de aspectos da natureza da ciência; melhorar a atitude dos estudantes em relação à ciência, motivando-os; envolver os alunos em debates históricos para promover a competência em usar argumentos estruturantes; e desenvolver metacognição, aumentando a capacidade de aprender sobre os processos de pensamento a partir do envolvimento em debates históricos.

O presente artigo tem como objetivos, em um primeiro momento, identificar as referências filosóficas e pedagógicas declaradas pelos autores de teses e dissertações brasileiras que defendam o ensino de história da ciência na educação científica no último decênio. A seguir, a investigação buscou os objetivos manifestados pelos autores para o uso didático da história e filosofia da ciência, também se e como eles articulam os referenciais adotados com a abordagem na educação científica de história e filosofia da ciência. Por fim, procura-se fazer uma análise de como os resultados encontrados podem refletir a pesquisa em educação científica. 


\section{METODOLOGIA E PRINCIPAIS RESULTADOS}

Para alcançar os objetivos deste trabalho, foi realizado um levantamento na produção de programas de pós-graduação em educação científica, principalmente em mestrados acadêmicos e doutorados, mas incluíram também mestrados profissionais. Apesar da ênfase nesses programas, eventualmente foram incluídos trabalhos de outras pós-graduações, relativos ao tema da revisão bibliográfica. Neste caso, e em particular, foram investigadas teses oriundas de programa de pós-graduação em educação, física, ensino, filosofia e história das ciências. Dentre as pós-graduações analisadas, onze apresentavam trabalhos que defendiam o uso didático da história da ciência, sendo sete em educação científica. O período examinado se estende de 2005 a 2014.

A busca foi feita inicialmente nos sítios dos programas de pós-graduação em educação científica que oferecem cursos de doutorado e mestrado acadêmicos. Primeiramente, foram examinados os títulos dos trabalhos e seus resumos. A atenção dirigiu-se às produções que envolviam o uso didático da história da ciência em geral, e da história da física e da química em particular. Aqueles de interesse para os fins da pesquisa foram, a seguir, analisados para averiguar como tratavam as questões de interesse deste trabalho, com sua leitura na íntegra.

Foram selecionados 41 trabalhos de 11 programas de pós-graduação, sendo 33 dissertações de mestrado e oito teses de doutorado. A relação das universidades, programas de pós-graduação e a quantidade de trabalhos analisados em cada instituição são apresentados na Tabela 1. Os títulos dos estudos encontram-se no Anexo 1. As teses de doutorado são identificadas por D1 a D8, e as dissertações de mestrado por M1 a M33.

Tabela 1: quantidade e origem dos trabalhos analisados

\begin{tabular}{|c|c|c|c|}
\hline Universidade & Programa de Pós Graduação & Dissertações & Teses \\
\hline UFSM & Educação em Ciências & 1 & 1 \\
\hline UFRGS & Física & 1 & 1 \\
\hline UFRGS & Ensino de Física & 1 & 0 \\
\hline UFSC & Educação Científica e Tecnológica & 6 & 1 \\
\hline UFPR & Educação em Ciências e em Matemática & 4 & 0 \\
\hline UEL & Ensino de Ciência e Educação Matemática & 2 & 0 \\
\hline USP & Ensino de Ciências & 2 & 1 \\
\hline USP & Educação & 0 & 1 \\
\hline UNICAMP & Educação & 1 & 2 \\
\hline CEFET/RJ & Ensino de Ciências e Matemática & 15 & 0 \\
\hline UFBA & Ensino, Filosofia e História das Ciências & 0 & 1 \\
\hline Total & & 33 & 8 \\
\hline
\end{tabular}

A análise dos trabalhos procurou identificar: (i) a visão filosófica da ciência subjacente à investigação; (ii) a fundamentação educacional da pesquisa, em termos de teorias de aprendizagem; (iii) as justificativas para 
a abordagem didática da história e filosofia da ciência e (iv) a articulação entre os aportes educacional e filosófico. Alguns trabalhos analisados não têm como foco principal o uso didático de história e filosofia da ciência, e são voltados principalmente, por exemplo, para a formação de professores e para livros didáticos. Não obstante, quando eles defendem, em algum momento, o uso didático de história e filosofia da ciência isto subjaz uma necessidade de fundamentação epistemológica (FORATO et al, 2011) e como qualquer pesquisa, em educação científica de uma fundamentação teórica em educação (MOREIRA, 2004). Isso justifica os focos de análise, mesmo nesses trabalhos.

Dentre as pesquisas analisadas, quatorze, cerca de 34\%, não declararam seu aporte filosófico ao defenderem o uso didático da história e filosofia da ciência. Thomas Kuhn foi o filósofo mais usado como referência, em cerca de $29 \%$ dos trabalhos. Aproximadamente $22 \%$ dos autores alinharam-se às críticas de vários filósofos da ciência a visão empírico-indutivista. Outras visões filosóficas utilizadas foram as de Paul Feyerabend, Stephen Toulmin, Gaston Bachelard, Bruno Latour e Imre Lakatos.

Dentre as teses de doutorado, apenas uma, a D3 (12,5\%), não declarou seu aporte filosófico. A D6 utilizou como referência Thomas Kuhn e Stephen Toulmin. Dois trabalhos, D1 e D7 (25\%), valeram-se da rejeição à filosofia empírico-indutivista. Quatro ${ }^{1}$ estudos $(50 \%)$ usaram a filosofia de Thomas Kuhn como aporte teórico. Gaston Bachelard fundamentou a tese D8.

Dentre as pesquisas de mestrado, treze ${ }^{2}$ trabalhos, (40\%), não declararam sua fundamentação filosófica. Thomas Kuhn foi mencionado por oito ${ }^{3}$ autores (24\%). A dissertação M2 mencionou Paul Feyerabend, M14 se referiu a Imre Lakatos, e M30 a Bruno Latour.

Sete $^{4}$ trabalhos (21\%) utilizaram uma espécie de base filosófica comum entre filósofos da ciência contemporânea como contraponto ao modelo empíricoindutivista. A dissertação M19 (3\%) se declarou filiada a entendimentos filosóficos que recusam a visão ateórica, a-histórica, algorítmica e individualista da ciência, enquanto M8 aderiu à fundamentação de dois autores, Bachelard e Kuhn. O Gráfico 1 mostra um resumo desta primeira análise.

Gráfico 1: Alinhamentos filosóficos declarados pelos autores das dissertações e teses

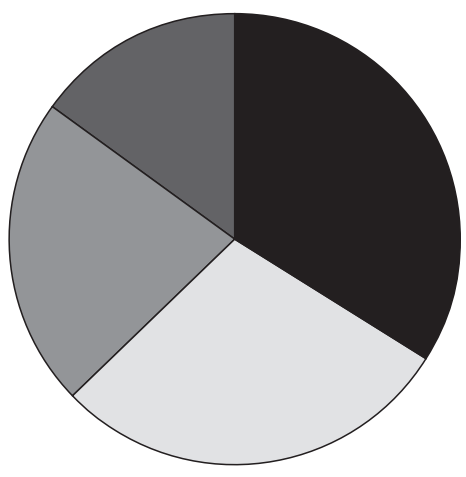

Legenda:

- $34 \%$ Nenhum (n: 14 )

29\% Thomas Kuhn (n: 12)

$22 \%$ Base episteológica com algumas características que se contrapõem ao indutivismo (n: 9)

$15 \%$ Outras (n: 6) 
Em relação à filiação educacional, 26 (63\%) não declararam qual teoria de aprendizagem orientou o desenvolvimento da pesquisa. As teorias mais citadas foram as da aprendizagem significativa de Ausubel e da transposição didática de Chevallard (7\% e 5\%, respectivamente). Também foram mencionadas a perspectiva sociointeracionista de Vigostski, a de Paulo Freire, a transposição didática de Gagliard e Astolfi, a teoria educacional de Bob Gowin e a Teoria da Aprendizagem Significativa Crítica de Moreira.

Em relação às teses de doutorado, apenas em D5 (12,5\%) não foi encontrada fundamentação educacional. $\mathrm{O}$ aporte mais usado foi a transposição didática de Chevallard, por D3 e D7 (25\%). D4 (12,5\%) também utilizou Chevallard como fundamentação, juntamente com a perspectiva de Paulo Freire. A Teoria da Aprendizagem Significativa de Ausubel, a transposição didática de Gagliard e Astolfi e a perspectiva sociointeracionista de Vigostski fundamentaram, respectivamente, as teses D1, D2 e D6. A tese D8 (12,5\%) valeu-se de um referencial construtivista dos processos de ensino e aprendizagem, tendo como ponto de partida a trajetória das pesquisas sobre as concepções alternativas e sobre os modelos de mudança conceitual.

Entre as dissertações de mestrado, em um grande número não existe uma fundamentação educacional. Há $25^{5}$ trabalhos sem aporte educacional $(76 \%)$. Todavia, M14 e M23 (6\%) mencionaram a Teoria da Aprendizagem Significativa de Ausubel. A investigação M26 fez referência a Ausubel, juntamente com a Teoria da Aprendizagem Significativa Crítica de Moreira. M2 citou como aporte duas teorias, a de Ausubel e a de Vigostsky. O estudo M3 manifestou-se alinhado à teoria de Moreira. Paulo Freire é citado por uma dissertação, a M30. Já M19 tece críticas à transposição didática de Chevallard, e M14 usa como aporte a teoria educacional de Bob Gowin. O Gráfico 2 resume os resultados relativos à análise desse segundo ponto.

Gráfico 2: Alinhamentos educacionais declarados pelos autores de teses e dissertações

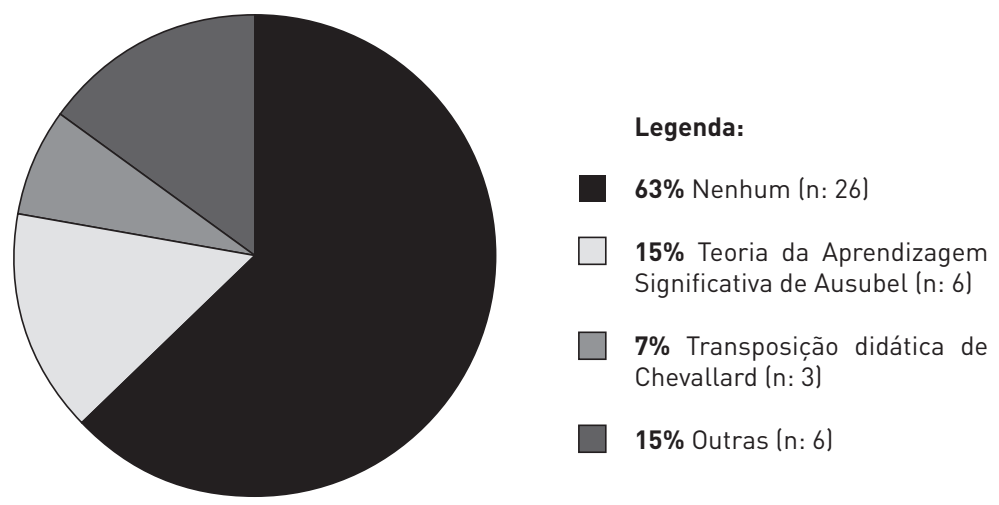


Em relação às justificativas dos autores para o uso didático da história e filosofia da ciência, a grande maioria dos trabalhos analisados descreveu alguma motivação. No entanto, houve uma diversidade de argumentos para tal defesa. Para analisar essa grande quantidade de dados, optou-se por uma técnica muito utilizada no processo não estatístico de interpretação - a teoria fundamentada. Segundo Strauss e Cobin (2009), trata-se de uma análise na qual o pesquisador não tem concepções prévias, ele permite que elas surjam a partir da sua interpretação dos dados. Nesse estudo, a partir da análise das justificativas, foram traçadas quatro categorias.

Por vezes, alguns autores recorrem a mais de uma categoria, por isso o número total de citações é maior do que o número total de trabalhos analisados. A mais frequente foi (1) à possibilidade de se discutir a natureza da ciência e mostrála como uma construção humana; quarenta estudos usaram tal justificativa. A segunda mais comum foi (2) a de tornar o aluno crítico e/ ou reflexivo, citada por 27 trabalhos, seguida por (3) ajudar na compreensão dos conceitos de ciência, mencionada por 23 investigações. O quarto padrão de justificação mais recorrente foi (4) à possibilidade de desconstrução da visão de ciência como um assunto difícil e assim poder aumentar a predisposição em aprender esta área, por doze trabalhos.

Em relação às dissertações de mestrado, 32 se enquadraram na primeira categoria (exceto a investigação M26); $20^{6}$ (61\%) na segunda, $19(58 \%)$ na terceira ${ }^{7}$ e $11^{8}(30 \%)$ investigações na quarta.

Entre as teses de doutorado, oito recorreram à primeira categoria; sete ao segundo padrão, exceto D4; quatro ${ }^{9}$ na terceira e apenas uma, D1, na quarta categoria.

O Gráfico 3 resume os dados das justificativas mais recorrentes.

Gráfico 3: Padrões recorrentes para justificar o uso didático de história e filosofia da ciência na educação científica

$$
\begin{array}{r}
\text { Possibilidade de aumentar a } \\
\text { predisposição em aprender (n: 12) } \\
\text { Possibilidade de ajudar na compreensão } \\
\text { dos conceitos de ciência (n: 23) } \\
\text { Possibilidade de tornar o aluno crítico } \\
\text { e/ou reflexivo (n: 27) } \\
\text { Possibilidade de se discutir a natureza da } \\
\text { ciência e mostrá-la como uma construção } \\
\text { humana (N: 40) }
\end{array}
$$

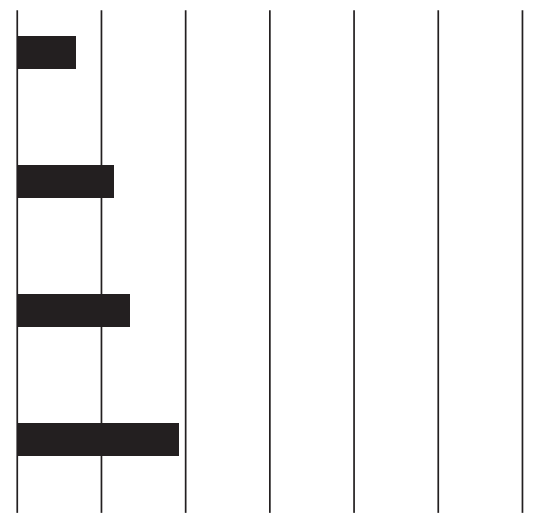


Em relação à articulação entre os aportes educacionais e filosóficos, apenas os trabalhos que apresentaram os dois aportes foram considerados nesta análise. Dentre as teses de doutorado, quatro ${ }^{10}$ conceberam tal articulação. O estudo D4, que adotou como diretriz pedagógica Paulo Freire, defende que os conhecimentos advindos das reflexões históricas e filosóficas contemporâneas se contrapõem às dos estudantes. Diante disso, sustenta a necessidade da relação dialógica, do diálogo problematizador em torno das preconcepções históricofilosóficas do educando. Para que a cultura primeira do educando seja superada, o educador precisa compreendê-la, para, por meio da problematização, criar o estímulo para a sua superação. A investigação D6, que adotou como referencial a perspectiva educacional sociointeracionista de Lev Vigotski, sugere estratégias de ensino voltadas para a promoção de atividades em grupos concebidas com a ideia de que o conhecimento é construído pelo sujeito por meio de um processo de interação social. O estudo oferece uma alternativa de como fazer uso didático da história e filosofia da ciência com a perspectiva de propiciar a habilidade dos alunos em construir coletivamente uma argumentação sobre esse assunto.

A pesquisa D7, que usou como referencial pedagógico a teoria da transposição didática de Yves Chevallard, justifica sua articulação com o uso didático da história da ciência por conceber que certos aspectos da transposição didática podem contribuir para se entender alguns requisitos necessários à adaptação dos saberes da história e filosofia da ciência no ambiente escolar. O estudo ainda sugere indicadores que podem guiar a transposição didática para o uso didático da história da ciência. Entre eles, é necessário esclarecer qual concepção de ciência será adotada e os aspectos filosóficos que serão trabalhados, assim como a falta de 'pré-requisitos' dos alunos. O estudo D8 declara ter um referencial construtivista dos processos de ensino e aprendizagem, tendo como ponto de partida a trajetória das pesquisas sobre as concepções alternativas e sobre os modelos de mudança conceitual. Para o autor, a utilização da História da Ciência no ensino não significa apenas a sua inclusão nos cursos de Ciências, mas também a sua utilização como uma ferramenta na definição de conteúdos fundamentais no ensino. Na fundamentação de tal proposta, a noção de "conceitos estruturantes" tem destaque, uma vez que define noções que, ao serem construídas pelo indivíduo, auxiliam a construção de novos conhecimentos. Isso sugere a utilização no ensino de "conceitos estruturantes", que estiveram presentes em momentos históricos de profunda transformação.

Dentre as dissertações de mestrado, as cinco ${ }^{11}$ que apresentaram os dois aportes explicitaram a articulação entre eles. O estudo M2, que declara fundamentação nas teorias de Ausubel e Vigostsky, defende que a história da ciência pode se constituir como organizador prévio ao fomentar a criação de concepções decorrentes da atividade de questionamento acerca dos conceitos a serem abordados. Também, a história da ciência pode promover inquietação ao discutir a natureza da ciência. $\mathrm{O}$ estudo sustenta que a interação nas aulas de física é essencial para mostrar que nosso conhecimento é uma iniciativa humana, intricada e demorada. 
O estudo M14 declara fundamentação em Gowin, para quem o sentimento de significância está ligado diretamente à efetiva compreensão do que se está aprendendo. $\mathrm{O}$ material educativo proposto, com abordagem de história e filosofia da ciência, serve justamente à intenção de promover uma sequência que torne factível o crescimento de significados e relações, que culminem em novas experiências, em novos eventos cognitivos para o aluno. A investigação M18, que declara alinhamento com a teoria de Ausubel, defende que, quando estudantes têm crenças parcialmente adequadas da natureza da ciência, essa estabilidade organizacional serve de elo às novas ideias. Essa relação com ideias prévias pode produzir, como resultado, uma concepção diferenciada e mais adequada de concepções científicas.

A dissertação M19, que critica a transposição didática de Chevallard, defende que essa didática descontextualizadora, além de propagar equívocos sobre a natureza da ciência e do trabalho científico, também falha quando, inadvertidamente, faz uso de conceitos estranhos ao quadro conceitual de origem em que são abordados determinados assuntos. A utilização da história da ciência, nesse cenário, funciona como mero conteúdo introdutório, pois o processo envolve a apresentação de conteúdos organizados de forma lógica, sem preocupações com as origens histórico-filosóficas do contexto de geração desses conhecimentos. A investigação M26 usou a Teoria da Aprendizagem Significativa Crítica para produzir texto didático abordando história da ciência e também orientou sua utilização em ambiente de ensino. Os princípios da teoria orientaram tanto a elaboração como a aplicação do produto, procurando deslocar a centralidade recorrente da educação cientifica do ensino básico nos livros de texto. O estudo M30, ancorado na pedagogia de Paulo Freire, defende um ensino científico que seja dialógico. Dessa forma, não pode abrir mão da dimensão histórica e problematizadora. Assim se justifica que a história e filosofia da ciência devam fazer parte da cultura científica, como uma história que problematize o conhecimento físico, e que seja, além de uma ponte à filosofia, um convite a filosofar.

A Tabela 2 procura sintetizar os dados analisados, fornecendo uma visão geral sobre quais trabalhos têm ou não as características investigadas. 
Tabela 2: Visão geral da análise

\begin{tabular}{|c|c|c|c|c|}
\hline Trabalho & $\begin{array}{l}\text { Apresenta aporte } \\
\text { filosófico }\end{array}$ & $\begin{array}{l}\text { Apresenta } \\
\text { aporte } \\
\text { educacional }\end{array}$ & $\begin{array}{c}\text { Apresenta } \\
\text { articulação entre } \\
\text { os aportes }\end{array}$ & $\begin{array}{l}\text { Justificativas para } \\
\text { uso didático de HFC }\end{array}$ \\
\hline D1 & Sim & Sim & Não & (1), (2) \\
\hline D2 & Sim & Sim & Não & (1), (2) \\
\hline D3 & Não & Sim & Não se aplica & (1), (2), (3) \\
\hline D4 & Sim & Sim & Sim & $(1),(3),(4)$ \\
\hline D5 & Sim & Não & Não se aplica & (1), (2), (3) \\
\hline D6 & Sim & Sim & Sim & $(1),(2),(4)$ \\
\hline $\mathrm{D} 7$ & Sim & Sim & Sim & $(1),(2),(4)$ \\
\hline $\mathrm{D} 8$ & Sim & Sim & Sim & $(1),(2),(3),(4)$ \\
\hline M1 & Sim & Não & Não se aplica & (1), (2) \\
\hline M2 & Sim & Sim & Sim & (1), (2), (4) \\
\hline M3 & Não & Sim & Não se aplica & (1), (3) \\
\hline M4 & Sim & Não & Não se aplica & $(1),(2),(3)$ \\
\hline M5 & Não & Não & Não se aplica & (1) \\
\hline M6 & Não & Não & Não se aplica & $(1),(2),(3),(4)$ \\
\hline M7 & Sim & Não & Não se aplica & $(1),(2),(3),(4)$ \\
\hline M8 & Sim & Não & Não se aplica & (1), (2), (3) \\
\hline M9 & Sim & Não & Não se aplica & $(1),(2),(3),(4)$ \\
\hline M10 & Sim & Não & Não se aplica & (1), (2) \\
\hline M11 & Não & Não & Não se aplica & (1), (2), (3) \\
\hline M12 & Não & Não & Não se aplica & (1), (2), (3) \\
\hline M13 & Sim & Não & Não se aplica & $(1),(2),(3),(4)$ \\
\hline M14 & Sim & Sim & Sim & (1), (3), (4) \\
\hline M15 & Sim & Não & Não se aplica & (1), (3), (4) \\
\hline M16 & Sim & Não & Não se aplica & $(1),(2)$ \\
\hline M17 & Não & Não & Não se aplica & $(1),(2)$ \\
\hline M18 & Sim & Sim & Sim & $(1),(2),(3),(4)$ \\
\hline M19 & Sim & Sim & Sim & (1), (3), (4) \\
\hline M20 & Não & Não & Não se aplica & (1) \\
\hline M21 & Não & Não & Não se aplica & $(1),(2),(3)$ \\
\hline M22 & Sim & Não & Não se aplica & (1) \\
\hline M23 & Não & Sim & Não se aplica & (1), (2), (3) \\
\hline M24 & Não & Não & Não se aplica & $(1),(2)$ \\
\hline M25 & Sim & Não & Não se aplica & (1), (3) \\
\hline M26 & Não & Sim & Não se aplica & (4) \\
\hline M27 & Não & Não & Não se aplica & (1) \\
\hline M28 & Sim & Não & Não se aplica & (1), (3) \\
\hline M29 & Sim & Não & Não se aplica & (1), (2), (3) \\
\hline M30 & Sim & Sim & Sim & $(1),(2)$ \\
\hline M31 & Sim & Não & Não se aplica & $(1),(3)$ \\
\hline M32 & Sim & Não & Não se aplica & $(1),(2)$ \\
\hline M33 & Não & Não & Não se aplica & (1), (4) \\
\hline
\end{tabular}




\section{DISCUSSÃO}

A discussão que se segue em relação aos dados apresentados anteriormente é pautada principalmente nas recomendações de Moreira (2004, 2009) para a pesquisa na educação científica. Obviamente, isso não exclui outros possíveis referenciais teóricos.

Pesquisar é produzir conhecimentos dentro de um marco teórico, metodológico e filosófico consistente e coerente (MOREIRA, 2009). Isso exige uma permanente interação entre o domínio metodológico e teórico. Schnetzler (2002) enfatiza que os pesquisadores em ensino de ciências abordam as interações entre pessoas, além da dinâmica do conhecimento em um ambiente de ensinoaprendizagem.

Moreira (2004) argumenta que, o conteúdo específico das ciências deve sempre estar presente na pesquisa em ensino de ciência. O autor destaca que um ponto frágil de muitos estudos é que autores relegam o conteúdo científico a um nível bem inferior em suas pesquisas. Ainda de acordo com o pesquisador, mesmo que a área da pesquisa em ensino de ciência necessite de contribuições de outras áreas, ela não pode deixar de fora o conhecimento científico propriamente dito.

A necessidade de um marco filosófico para a pesquisa em ensino de ciência pode ser entendida, por exemplo, quando se entende que as pesquisas têm mostrado que a visão de professores e alunos sobre o conhecimento científico tem efeito sobre o seu ensino-aprendizagem (PUJALTE et al, 2014). Moreira (2009) ressalta a importância de que professores e pesquisadores da área da educação científica tenham consciência dessa influência. Sendo seu campo de interesse o ensino e aprendizagem de ciência, "é preciso aprender sobre teorias de aprendizagem e desenvolvimento cognitivo, sobre metodologias de pesquisa em educação e sobre filosofia da ciência" (op. cit, p. 4). Logo, na visão do autor, a pesquisa em educação científica necessita de um aporte filosófico articulado e coerente com o educacional e metodológico.

Não obstante, tão prejudicial quanto ignorar didaticamente a história e filosofia da ciência seria sobrevalorizá-la. A abordagem histórico-filosófica não pode ser entendida como a solução de todos os problemas da educação científica, mas sua inserção se mostra como um recurso útil de diversas maneiras: incrementa a cultura geral dos alunos; desmistifica o método científico; mostra como o pensamento científico se modifica ao longo do tempo; chama a atenção para a importância das ideias metafísicas e contribui para o entendimento da relação da ciência com a cultura, sociedade e tecnologia (PEDUZZI, 2001).

Apesar de acreditar que a pesquisa em ensino de ciências hoje seja um campo consolidado, Moreira (2004) expressa algumas debilidades e dificuldades. Entre elas, justamente trabalhos sem referencial teórico, filosófico e metodológico adequado e coerente. Em particular, aponta para um grande número de estudos sem marco teórico ou com um suposto aporte que não se articula com o objeto estudado.

Dentro dessa perspectiva, pode-se discutir as informações levantadas nas dissertações e teses examinadas anteriormente. O primeiro ponto relevante diz respeito à ausência de um aporte educacional em 63\% dos trabalhos. Outro dado importante é que, em 34\% deles, não foi possível identificar uma fundamentação 
filosófica. Esses dados reforçam as debilidades da pesquisa em ensino de ciências levantadas por Moreira. Não obstante, mesmo quando em algumas situações os autores declaram aporte teórico, esse não se articula com o objeto estudado. Essa questão parece bastante relevante quando se analisa o dado de que apenas pouco mais de um quarto dos trabalhos examinados anteriormente explicitaram tal relação. Considerando-se que são trabalhos de pesquisadores da área da educação científica em formação e que terão influência na área nos próximos anos, a informação se apresenta com um significado ainda maior.

No que diz respeito à questão das justificativas levantadas pelos autores, também parece haver pontos a ser levantados. Muitos pesquisadores da área que defendem o ensino de história e filosofia da ciência na educação científica o fazem em favor de uma abordagem "contextualista", em seus diversos contextos: histórico, ético, social, filosófico e tecnológico (MATTHEWS, 1995). Também, por contribuir para uma imagem mais adequada da natureza da ciência e do processo de desenvolvimento do conhecimento científico (GUERRA et al, 2004).

A primeira categoria traçada para as justificativas dos autores se refere ao padrão quase universal usado para justificar o uso didático de história e filosofia da ciência: possibilidade de se discutir a natureza da ciência. Esse dado é relevante, mas não necessariamente negativo, pois mostra algum consenso entre pesquisadores da área. No entanto, conforme ressaltam Forato et al (2011), qualquer narrativa histórica encerra uma visão de ciência e sobre os seus processos de construção. "Ao se construir, utilizar ou divulgar uma determinada versão da HC, está se propagando uma concepção de como a ciência foi construída" (op.cit., p. 30). E a ausência de aporte epistemológico compromete essa pretensão de grande parte dos autores analisados. Além disso, deve-se ponderar que a própria expressão 'natureza da ciência' é muito recente entre pesquisadores brasileiros.

Assim, quando os autores colocam a questão de discutir a natureza da ciência, eles trazem, como justificativas, afirmações do tipo "mostrar de que modo a ciência funciona" ou "desmistificar o empreendimento científico". Porém, tais afirmações são vagas filosoficamente. Isso porque o entendimento do que se entende por natureza da ciência depende do referencial filosófico adotado. Por conseguinte, quando se sugere discutir a natureza da ciência deve estar claro de que natureza da ciência se está tratando, pois visões de filósofos racionalistas como Mario Bunge e de relativistas como Paul Feyerabend têm poucos pontos de concordância em relação a essa questão. Moura (2014) expressa bem esse fato, ao fazer uma extensa revisão bibliográfica, em nível internacional e nacional, sobre o emprego do conceito de natureza da ciência nas últimas três décadas. O resultado de sua análise foi que se pode entender que a natureza da ciência se refere a elementos envolvidos na construção do conhecimento científico, desde questões internas até as externas. Abrigam-se temas relacionados ao método científico, relação entre teoria e observação, bem como o papel da criatividade e das concepções prévias dos cientistas na elaboração de suas ideias. A concepção do entendimento acerca da natureza da ciência depende de orientações ideológicas e filosóficas.

Como em mais de um terço de trabalhos não foi possível identificar a fundamentação filosófica, a articulação com os aportes teóricos e metodológicos fica inviável. Dessa forma, segundo a visão de Moreira, esses trabalhos tendem a se alinhar 
a uma das debilidades da pesquisa em educação de ciências apontadas pelo autor.

O segundo padrão mais recorrente merece também uma análise detalhada: tornar o aluno crítico e/ ou reflexivo. Grande parte dos trabalhos acredita que a simples discussão de história e filosofia da ciência permite formar alunos mais críticos e reflexivos. A afirmação de que a abordagem desses temas formará pessoas mais críticas parece pouco fundamentada. Inicialmente, porque não se discute, na maioria dos casos, o que se entende por uma pessoa crítica e sob qual aporte teórico se constrói essa definição.

As duas outras categorias mais recorrentes de justificativas para o uso didático de história e filosofia da ciência também fazem jus a uma análise. Tanto a justificativa de ajudar na compreensão dos conceitos de ciência, como a possibilidade de desconstrução da visão de ciência como um assunto difícil e assim poder aumentar a pré-disposição em aprender essa área ficam um pouco vagas sem um aporte em termos de teorias de aprendizagem. Em relação a esses dados, cabe uma reflexão de que existe pouca atenção, em grande parte dos estudos, em relação à questão de como as pessoas aprendem. Isso é relevante quando se pensa em sugerir o uso didático de algum conhecimento, para um público específico como o da educação científica. Para tanto, é fundamental existir a coerência da proposta com um aporte em teoria de aprendizagem. Como tal fundamentação está ausente em $63 \%$ dos trabalhos, parece ocorrer também aqui uma das dificuldades da área da educação científica apontadas por Moreira (2004).

\section{CONSIDERACְÕES FINAIS}

Conforme defende Delizoicov (2004), existem indicativos claros de que existe uma comunidade de pesquisadores em ensino de ciências no Brasil, tais como: eventos científicos, periódicos e produção de dissertações e teses. Tal comunidade produz e divulga suas pesquisas. A comunidade de pesquisadores em ensino de ciências deve tirar lições do passado desse campo, realizando as correções necessárias de acordo com os equívocos cometidos.

Ao conceber as perspectivas para a educação científica na educação básica, Moreira (2000) enfatiza que não faz sentido ensinar ciência como se os alunos da educação básica fossem cientistas em potencial - o que o pesquisador aponta como grande erro de muitos projetos curriculares. Também Schnetzler (2002), ao apresentar o seu entendimento do ensino de ciências, recomenda que as universidades invistam em propostas para incentivar a pesquisa em educação científica, para que a investigação e a produção acadêmica possam contribuir para a compreensão dos processos de ensinar e aprender.

A revisão bibliográfica das teses e dissertações brasileiras no último decênio pode ser útil para identificar uma tendência dos novos pesquisadores em ensino de ciência acerca da questão do uso didático de história e filosofia da ciência. Um primeiro aspecto que chama a atenção é que, apesar de o artigo se referir à educação científica e de grande parte dos programas estudados abrangerem, em princípio, todas as ciências, encontra-se o predomínio de trabalhos de física e química e uma escassez de trabalhos de biologia e outras ciências. Essa lacuna parece estar sendo 
preenchida por iniciativas como a criação do Mestrado Profissional em Ensino de Biologia em Rede Nacional (ProfBio), ligado à UFMG.

O resultado mais significativo, nesta análise dos trabalhos, ao que parece, é que a grande maioria ainda tem foco no ensino e não na aprendizagem, tratando-a como uma consequência natural do que consideram boas abordagens instrucionais. A maioria dos pesquisadores em formação na área de pesquisa em ensino de ciência na última década, analisados nesta revisão, parece dar pouca ou nenhuma importância para como as pessoas aprendem. Isso preocupa quando se tem em perspectiva que essa foi justamente a causa de infortúnios em pesquisas em ensino de ciências desde a década de 1960. Logo, um grande número de pesquisadores parece não ter levado em consideração os equívocos que as pesquisas na área cometeram no passado para fazer as correções necessárias, conforme sugere Delizoicov (2004). Existe hoje, uma área estabilizada na pesquisa em ensino de ciência. Ainda segundo o autor, a pesquisa em ensino de ciências se constitui em um campo social de produção de conhecimento, tendo como característica sua autonomia em relação a outras áreas, mas mantendo inter-relações em diversos níveis de aproximação.

Moreira (2004) faz recomendações para superar as debilidades elencadas por ele. Entre elas: melhorar as pesquisas em termos de fundamentação teórica, filosófica e metodológica e distinguir entre pesquisa e inovação. Quando se consideram as recomendações feitas por Moreira ao analisar os trabalhos de mestrado e doutorado na área de ensino de ciência, que defendem o uso didático de história e filosofia da ciência, percebe-se, com clareza, a fundamentação das preocupações do autor. Os resultados mostraram muitas das debilidades apontadas por ele na pesquisa em educação científica, principalmente a falta de aporte teórico, filosófico e metodológico. Bem como, quando existe tal fundamentação, ausência de articulação e coerência entre elas. Como se trata de pesquisadores da área em formação, tais dados podem e devem causar uma reflexão em relação ao desenvolvimento e credibilidade da própria área de pesquisa em educação científica.

Ao final, pode não ter ficado claro para o leitor como fazer, de modo efetivo, a aproximação do uso da história e filosofia da ciência, por um lado, e as teorias educacionais, por outro. Existem trabalhos recentes que procuram fazer exatamente tal aproximação. Damasio e Peduzzi (2015), por exemplo, constroem teoricamente a coerência e complementaridade entre o aporte da filosofia da ciência de Feyerabend e a Teoria da Aprendizagem Significativa Crítica, visando ao uso didático de história da ciência. Esse tipo de aproximação é o que Moreira (2004) recomenda para uma pesquisa em educação científica sem as debilidades por ele apontadas.

\section{NOTAS}

${ }^{1}$ D2, D4, D5 e D6.

${ }^{2}$ M3, M5, M6, M11, M12, M17, M20, M21, M23, M24, M26, M27 e M33.

${ }^{3}$ M1, M4, M7, M10, M16, M31 e M32. 


\author{
${ }^{4}$ M13, M15, M18, M22, M25, M28 e M29. \\ ${ }^{5}$ M1, M4, M5, M6, M7, M8, M9, M10, M11, M12, M13, M15, M16, M17, M20, M21, M22, M24, \\ M25, M27, M28, M29, M31, M32 e M33. \\ ${ }^{6}$ M1, M2, M4, M6, M7, M8, M9, M10, M11, M12, M13, M16, M17, M18, M21, M23, M24, M29, \\ M30 e M32. \\ ${ }^{7}$ M3, M4, M6, M7, M8, M9, M11, M12, M13, M14, M15, M18, M19, M21, M23, M25, M28, M29 \\ e M31. \\ ${ }^{8}$ M2, M6, M7, M9, M13, M14, M15, M18, M19, M26 e M33. \\ ${ }^{9}$ D3, D4, D5 e D8. \\ ${ }^{10}$ D4, D6, D7 e D8. \\ ${ }^{11}$ M2, M14, M18, M19 e M30.
}

\title{
REFERÊNCIAS
}

AGUIAR JR., O. Mudanças conceituais (ou cognitivas) na educação em ciências: revisão crítica e novas direções para a pesquisa. Ensaio Pesquisa em Educação em Ciência, v. 3, n. 1, p. 1-25, 2001.

DAMASIO, F.; PEDUZZI, L. O. Q. Coerência e complementaridade entre a epistemologia de Paul Feyerabend e a teoria da aprendizagem significativa crítica. Investigações em Ensino de Ciências, v. 20, n. 3, p. 61-83, 2015.

DELIZAICOV, D. Pesquisa em ensino de ciências como ciências humanas aplicadas. Cad. Bras. Ens. Fís., v. 21: p. 145-175, 2004.

FORATO, T. C. M.; PIETROCOLA, M.; MARTINS, R. A. Historiografia e natureza da ciência na sala de aula. Cad. Bras. Ens. Fís, v. 28, n. 1, p. 27-59, 2011.

GUERRA, A.; FREITAS, J. R.; BRAGA, M. Uma abordagem histórico-filosófica para o eletromagnetismo no ensino médio. Cad. Bras. Ens. Fís, v. 21, n. 2, p. 224-248, 2004.

KRAGH, H. Introdução à historiografia da ciência. Porto: Porto Editora, 2001.

MARTINS, A. F. P. História e filosofia da ciência no ensino: há muitas pedras neste caminho. Cad. Bras. Ens. Fís, v. 24, n. 1, p. 112-131, 2007.

MARTINS, R. A. Ciência versus historiografia: os diferentes níveis discursivos nas obras sobre história da ciência. In: ALFONSO-GOLDFARB, A. M.; BELTRAN, M. H. R. (org.) Escrevendo a história da ciência: tendências, propostas e discussões historiográficas. São Paulo: EDUC/Livraria Editora da Física/Fapesp, 2004, p. 115-146.

MATTHEWS, M. R. História, filosofia e ensino de ciências: a tendência atual de reaproximação. Caderno Catarinense de Ensino de Física, v. 12, n. 3, p. 164-214, 1995.

MOREIRA, M. A. Ensino de física no Brasil: retrospectiva e perspectivas. Revista Brasileira de Ensino de Física, v. 22, n. 1, p. 94-99, 2000. 
MOREIRA, M. A. A pesquisa em Educação em Ciências e a Formação Permanente do Professor de Ciências. Revista Chilena de Educación Científica, v. 3, n. 1, p. 10-17, 2004.

MOREIRA, M. A. Aprendizagem significativa crítica. Porto Alegre: Ed. do autor, 2005.

MOREIRA, M. A. Comportamentalismo, construtivismo e humanismo. Subsídios teóricos para o Professor Pesquisador em ensino de ciências. Porto Alegre: IF-UFRGS, 2009.

MOURA, B. A. O que é a natureza da ciência e qual sua relação com a história e filosofia da ciência? Revista Brasileira de História da Ciência, v. 7, n. 1, p. 32-46, 2014.

PEDUZZI. L. O. Q. Sobre a utilização didática de história da ciência. In: PIETROCOLA, M. (org.) Ensino de física: conteúdo, metodologia e epistemologia numa concepção integradora. Florianópolis: Editora da UFSC, 2001.

PUJALTE, A. P.; BONAN, L.; PORRO, S.; ADÚRIZ-BRAVO, A. Las imágenes inadecuadas de ciencia y de científico como foco de la naturaleza de la ciencia: estado del arte y cuestiones pendientes. Ciênc. Educ., v. 20, n. 3, p. 535-548, 2014.

RAICIK, A.; PEDUZZI, L. O. Q. Um resgate histórico e filosófico dos estudos de Charles Du Fay. Revista Ensaio, v. 17, n. 1, p. 105-125, 2015.

SCHNETZLER, R. P. A pesquisa em ensino de química no Brasil: conquistas e perspectivas. Quim. Nova, v. 25, supl. 1, 14-24, 2002.

SILVA, H.C.; WEISS, K.; COSTA, D. A.; VIEGAS, G. Produção de conhecimento sobre ensino de física na modalidade a distância: tendências, lacunas, novas questões. Cad. Bras. Ens. Fís, v. 29, n. especial 2, p. 708-728, 2012.

STRAUSS, A.; CORBIN, J. Pesquisa qualitativa: técnicas e procedimentos para o desenvolvimento de teoria fundamentada. Porto Alegre: ARTMED, 2009.

TEIXEIRA, E. S.; GRECA, I. M.; FREIRE JR., O. The history and philososophy in physics teaching: a research synthesis of didatic intervention. Science \& Education, v. 21, n. 6, p. 771-796, 2009.

\section{ANEXO 1 - RELAÇÃO DOS TRABALHOS ESTUDADOS}

D1 MASSONI, N. T. A epistemologia contemporânea e suas contribuições em diferentes níveis de ensino de física. 2010. 412 f. Tese (Doutorado em Física). Universidade Federal do Rio Grande do Sul, Porto Alegre, 2010.

D2 SILVA, D. N. Ensino e aprendizagem da termodinâmica: questões didáticas e contribuições da história da ciência. 2013. 259 f. Tese (Doutorado em Ensino de Ciências). Universidade de São Paulo, São Paulo, 2013.

D3 SEPEL, L. M. N. História da ciência e atividades práticas: propostas para a formação inicial de docentes. 2012. 166 f. Tese (Doutorado em Educação em Ciências). Universidade Federal de Santa Maria, Santa Maria, 2012.

D4 DANIEL, G. P. História da ciência em um curso de licenciatura em física: a gravitação newtoniana e a gravitação einsteniana como exemplares. 2011. 404 f. Tese (Doutorado em Educação Científica e Tecnológica). Universidade Federal de Santa Catarina, Florianópolis, 2011.

D5 SILVEIRA, H. E. A história da ciência em periódicos brasileiros de química: contribuições para a formação docente. 2008. 265 f. Tese (Doutorado em Educação). Universidade Estadual de Campinas. Campinas, 2008.

D6 TEIXEIRA, E. S. Argumentação e abordagem conceitual no ensino de física. 2010. 148 f. Tese (Doutorado em Ensino, Filosofia e História das Ciências). Universidade Federal da Bahia. Salvador, 2010 . 
D7 FORATO, T. C. M. A natureza da ciência como saber escolar: um estudo de caso a partir da história da luz. 2009. 220 f. Tese (Doutorado em Educação). Universidade de São Paulo. São Paulo, 2009. D8 GATTI, S. R. T. Análise de uma ação didática centrada na utilização da história da ciência: uma contribuição para a formação inicial do docente de física. 2005. 329 f. Tese (Doutorado em Educação). Universidade Estadual de Campinas. Campinas, 2005.

M1 FABRICIO, C. M. A abordagem histórica e filosófica da ciência nos livros didáticos de química - PNLDEM/2008 d PNLDEM/2012: um estudo sobre a combustão no século XVIII. 2014. 132 f. Dissertação (Mestrado em Educação em Ciência e em Matemática). Universidade Federal do Paraná. Curitiba, 2014.

M2 VIEIRA, P. C. Perspectiva sobre a evolução histórica do conceito de luz e sua integração com a fotografia para o ensino de óptica. 2014. 228 f. Dissertação (Mestrado em Ensino de Física). Universidade Federal do Rio Grande do Sul. Porto Alegre, 2014.

M3 SAVISKI, S. O. F. Uma abordagem didática com enfoque na história da física de plasma por meio da aprendizagem significativa. 2014. 135 f. Dissertação (Mestrado em Ensino de Ciências e Educação Matemática). Universidade Estadual de Londrina. Londrina, 2014.

M4 BEZERRA, E. V. L. Análise das propostas didáticas de história e filosofia da ciência para o ensino de física. 2014. 224 f. Dissertação (Mestrado em Educação em Ciências e em Matemática). Universidade Federal do Paraná. Curitiba, 2014.

M5 PÓVOAS, R. C. Ensino de física na EJA: uma abordagem histórica do eletromagnetismo. 2012. 117 f. Dissertação (Mestrado em Ensino de Ciências e Matemática). Centro Federal de Educação Tecnológica. Rio de Janeiro, 2012.

M6 SILVA, M. O. Ensino de máquinas térmicas através de um motor de Stirling motivado em uma abordagem histórica. 2012. 93 f. Dissertação (Mestrado em Ensino de Ciência e Matemática). Centro Federal de Educação Tecnológica. Rio de Janeiro, 2012.

M7 MEDEIROS, A. A. Análise da historiografia de Galileu e o movimento de queda dos corpos nos livros didáticos de física do ensino médio. 2013. 83 f. Dissertação (Mestrado em Ensino de Ciências e Educação Matemática). Universidade Estadual de Londrina. Londrina, 2013.

M8 ROCHA, T. U. As contribuições da história e filosofia da ciência para o ensino de física quântica na educação básica. 2013. 320 f. Dissertação (Mestrado em Educação em Ciências e em Matemática). Universidade Federal do Paraná. Curitiba, 2013.

M9 POPPOLINO, G. G. Utilizando a abordagem histórica com experimentação para trabalhar conceitos de química no ensino médio. 2013. 135 f. Dissertação (Mestrado em Ensino de Ciências e Matemática). Centro Federal de Educação Tecnológica. Rio de Janeiro, 2013.

M10 SCHIRMER, S. B. Textos originais de cientistas e textos sobre história das ideias da ciência em uma proposta didática sobre ótica na formação inicial de professores de física. 2012. 155 f. Dissertação (Mestrado em Educação em Ciências). Universidade Federal de Santa Maria. Santa Maria, 2012.

M11 ALCANTARA, M. C. História da ciência, filosofia e arte na Holanda do século XVII: construindo um módulo para o ensino dos instrumentos ótico. 2011. 66 f. Dissertação (Mestrado em Ensino de Ciências e Matemática). Centro Federal de Educação Tecnológica. Rio de Janeiro, 2011.

M12 BISCAINO, A. P. O enfoque histórico-filosófico da ciência no ensino e na formação inicial de professores de física: estudo de caso com licenciandos em situação de estágio de docência. 2012. 173 f. Dissertação (Mestrado em Educação em Ciências e em Matemática). Universidade Federal do Paraná. Curitiba, 2012. 
M13 PERON, T. S. História e filosofia no estudo da teoria da relatividade restrita no ensino médio. 2012. 202 f. Dissertação (Mestrado em Ensino de Ciências e Matemática). Centro Federal de Educação Tecnológica. Rio de Janeiro, 2012.

M14 ARTHURY, L. H. M. A cosmologia moderna à luz dos elementos da epistemologia de Lakatos. 2010. 133 f. Dissertação (Mestrado em Educação Científica e Tecnológica). Universidade Federal de Santa Catarina. Florianópolis, 2010.

M15 ARCANJO FILHO, M. Demanda epistemológica no ensino de física. 2011.93 f. Dissertação (Mestrado em Ensino de Ciências e Matemática). Centro Federal de Educação Tecnológica. Rio de Janeiro, 2011.

M16 FERNANDES, H. S. Narrativas históricas: discutindo a natureza da ciência através de uma abordagem histórico-filosófica. 2012. 133 f. Dissertação (Mestrado em Ensino de Ciências e Matemática). Centro Federal de Educação Tecnológica. Rio de Janeiro, 2012.

M17 JARDIM, W. T. A abordagem histórico-filosófica como caminho para se introduzir o estudo de cosmologia no ensino. 2012. 223 f. Dissertação (Mestrado em Ensino de Ciências e Matemática). Centro Federal de Educação Tecnológica. Rio de Janeiro, 2012.

M18 MASSONI, N. T. Estudo de caso etnográfico sobre a contribuição de diferentes visões epistemológicas contemporâneas na formação de professores de física. 2005. 275 f. Dissertação (Mestrado em Física). Universidade Federal do Rio Grande do Sul. Porto Alegre, 2005. M19 CORDEIRO, M. D. Dos Curie a Rutherford: aspectos históricos e epistemológicos da radioatividade na formação científica. 2011. 234 f. Dissertação (Mestrado em Educação Científica e Tecnológica). Universidade Federal de Santa Catarina. Florianópolis, 2011.

M20 PEREIRA, J. L. Controvérsia entre o modelo corpuscular e ondulatório da luz: um caminho para o ensino da óptica no nível médio. 2011. 98 f. Dissertação (Mestrado em Ensino de Ciências e Matemática). Centro Federal de Educação Tecnológica. Rio de Janeiro, 2011.

M21 MORAIS, A. V. O conceito de energia através da história: a história e a filosofia da ciência como caminho para inserir física moderna e contemporânea na primeira série do ensino médio. 2011. 191 f. Dissertação (Mestrado em Ensino de Ciências e Matemática). Centro Federal de Educação Tecnológica. Rio de Janeiro, 2011.

M22 BEZERRA, K. M. Resgatando a dimensão filosófica da física através de um texto paradidático. 2011. 94 f. Dissertação (Mestrado em Ensino de Ciências e Matemática). Centro Federal de Educação Tecnológica. Rio de Janeiro, 2011.

M23 TENFEN, D. N. Mapas conceituais como ferramenta para a organização do conhecimento em uma disciplina sobre a história da física. 2011. 206 f. Dissertação (Mestrado em Educação Científica e Tecnológica). Universidade Federal de Santa Catarina. Florianópolis, 2011. M24 MENEZES, A. M. S. Teoria da relatividade geral no ensino médio: linhas retas e curvas no caminho da física, da literatura e da história e filosofia da ciência. 2010. 99 f. Dissertação (Mestrado em Ensino de Ciências e Matemática). Centro Federal de Educação Tecnológica. Rio de Janeiro, 2010.

M25 SILVA, D. A. Aspectos epistemológicos da física newtoniana na formação científica. 2009. 196 f. Dissertação (Mestrado em Educação Científica e Tecnológica). Universidade Federal de Santa Catarina. Florianópolis, 2009.

M26 CRUZ, R. S. Tópicos de física moderna no ensino fundamental - a evolução do conceito de movimento, de Aristóteles a Einstein. 2009. 176 f. Dissertação (Mestrado em Ensino de Ciências e Matemática). Centro Federal de Educação Tecnológica. Rio de Janeiro, 2009. 
M27 DUQUE, E. R. História da ciência e o uso da instrumentação: construção de um aparato histórico-científico simples como estratégia de ensino. 2009. 90 f. Dissertação (Mestrado em Ensino de Ciências e Matemática). Centro Federal de Educação Tecnológica. Rio de Janeiro, 2009.

M28 SILVA, W. L. R. A importância de uma abordagem epistemológica na graduação em física. 2009. 147 f. Dissertação (Mestrado em Ensino de Ciências e Matemática). Centro Federal de Educação Tecnológica. Rio de Janeiro, 2009.

M29 MOURA, B. A. A aceitação da óptica newtoniana no século XVIII: subsídios para discutir a natureza da ciência no ensino. 2008. 214 f. Dissertação (Mestrado em Ensino de Ciências). Universidade de São Paulo. São Paulo, 2008.

M30 BARCELLOS, M. E. História, sociologia, massa e energia. Uma reflexão sobre a formação de pesquisadores em física. 2008. 152 f. Dissertação (Mestrado em Ensino de Ciências). Universidade de São Paulo. São Paulo, 2008.

M31 MONTENEGRO, A. G. P. A leitura de textos originais de Faraday por alunos do ensino fundamental e médio. 2005. 110 f. Dissertação (Mestrado em Educação). Universidade Estadual de Campinas. Campinas, 2005.

M32 MELO, A. C. S. Contribuições da epistemologia histórica de Bachelard no estudo da evolução dos conceitos da óptica. 2005. 198 f. Dissertação (Mestrado em Educação Científica e Tecnológica). Universidade Federal de Santa Catarina. Florianópolis, 2009.

M33 FLÔR, C. C. Leituras de professores de ciência no ensino fundamental sobre as histórias da ciência. 2005. 159 f. Dissertação (Mestrado em Educação Científica e Tecnológica). Universidade Federal de Santa Catarina. Florianópolis, 2005.

Submetido em 17/12/15

Aprovado em 28/12/16

\section{Contato:}

Felipe Damasio

Avenida XV de Novembro, 61 - Aeroporto

88905-112. Campus - IFSC-Araranguá. 
